\title{
Can 4-Day a Week be a New Working Week in the Days to come?
}

\author{
Dr. Tejashree Deshmukh \\ Dean-Academics \& Professor $-H R$ \\ PTVA's Institute of Management Mumbai, Maharashtra, India.
}

\begin{abstract}
:
Though the concept of 4-day a week is not really new and the reference to this practice is found to be as old as in the 1970s, the possibility of starting this practice on Corporate, is being explored again especially after the COVID 19 pandemic changed the way organizations operate globally. Recently, Cybersecurity Company, TAC Security announced on September 22, 2021 that it initiated a 4-day work week for its employees, starting their weekend on Fridays for the last 7 months to enhance the employee productivity. After this announcement, many organizations in India have developed an interest in this concept and are exploring the possibility of adopting it. Is this 4 day a week, a practical approach that can benefit the organizations, needs to be studied. This research paper tries to understand the concept of 4 day a week, its benefits, limitations and the possibility of adopting it in Indian Corporate scenario.

Keywords: 4-Day a Week, COVID 19 Pandemic, Employee Productivity, Adopting in India
\end{abstract}

\section{Introduction:}

COVID 19 pandemic led to drastic changes to every aspect of our lives including the way we think, feel, work, maintain our work-life balance and the way organizations operate. No-one imagined before COVID pandemic that we would work for our organizations, using remote access for months and years together. However, most of the businesses learnt to deal with this way of operating and while everyone started believing that this would become a New Normal for Work, the world started opening up and people started working using hybrid work model.

Recently, Cybersecurity Company, TAC Security announced on September 22, 2021 that it initiated a 4-day work week for its employees, starting their weekend on Fridays for the last 7 months to enhance the employee productivity. Since this news surfaced in the media, many Indian organizations are showing an interest in this concept and exploring the possibility of adopting it . The questions here to be explored are: i) Is this a new concept? ii) Does it enhance the employee productivity in a long run? iii) Is this a practical approach? iv) Is it inevitable in the future to come? 


\section{What is a 4 day Work Week?}

A 4 day Work Week is an approach related to alternative work arrangements. However, alternative work arrangements is a broader concept and includes many other approaches including flexitime, compressed work schedules, part-time work, telecommuting and more recently work from home.

A 4 day Work Week falls into the category of compressed work schedules where a work week is reduced to 4 working days per week, from 5 to 6 working days a week which is currently practised almost everywhere. A typical 5 day work week consists of around 40 to 45 hours a week in India. There are different views about how many hours a week should be included in a 4 day week and they vary from 32 hours a week to 40 hours a week to 46 hours a week, freeing an employee from work for remaining 3 days of a week.

Most of the proponents of 4 day a week are of the opinion that the employees should have a longer weekend starting from Friday itself each week. However, there is another school of thought which proposes that the $3^{\text {rd }}$ weekly off should be given to the employees in a staggered manner during the week and should not be clubbed with the weekend. (Bird 2010)

The advocates of 4 day work week are of the opinion that this work arrangement will allow the employees to have a better work-life balance and improve the productivity of the employees which in turn, will ensure higher organizational productivity.

\section{Is a 4-day Work Week a new Concept?}

Though the term 4 day a week is a new concept to many a common people in India which they heard for the first time after COVID 19 hit the world, the introduction of this term and even its application in the organizational set-up, can be traced back to early 1930s. A well-known economist John Maynard Keynes predicted in 1930 that in the next hundred years, a world will witness a 15-hour work week. Vice-president of the United States, Richard Nixon, envisioned a four-day work week was coming during his tenure in 1956. The first documented adoption of the four-day work week traces back to 1940 when the Mobil and Gulf Oil Companies started it for the truck drivers. (Bird 2010) In 1998, France enacted the first of its' two "Aubry" laws which reduced the national work week to 35 hours instead of 39, with excess hours counting as overtime. (Ellis 2018). Utah in United States introduced a 4 day work week in 2008 and continued with it till 2011. Iceland got a good response to the trails of a four-day week which took place between 2015 and 2019. In India, as mentioned above, Cybersecurity Company, TAC Security announced on September 22, 2021 that it initiated a 4-day work week for its employees, starting their weekend on Fridays for the last 7 months to enhance the employee productivity. Since then, this concept I getting a lot of attention from the Indian Corporate world.

\section{How does a 4-day Work Week benefit the Organizations?}

The proponents of a 4-day work week list a number of benefits that an organization will gain from this practice directly as well as indirectly. They include: 
1. More focussed approach related to Work: In a study conducted in New Zealand, it was found that a 4-day work week leads to more focussed approach toward the work by the employees. This practice creates a positive awareness among employees that their organization is taking care of their physical and mental well-being by reducing the number of days that the employees need to report to the organization and that too without affecting their paycheques. This feeling leads to the focussed work approach by the employees wherein they spend no or/ less office time on personal things such as a use of mobile phones, visiting various websites for personal use, spending office hours completing household chores, etc. It was also found that in such cases, the employees have shorter meetings which are totally focussed on the agenda to be discussed, without leaving any room for any other discussion. Helen Delaney, a senior lecturer at the University of Auckland Business School who also supervised the experiment, made a similar observation: "Employees designed a number of innovations and initiatives to work in a more productive and efficient manner, from automating manual processes to reducing or eliminating non-work-related internet usage." (Ellis 2018) "We have some good experiments showing that if you reduce work hours, people are able to focus their attention more effectively," opined Adam Grant, a psychologist from the Wharton School in Pennsylvania, US.

2. Better Work-Life Balance for the Employees: A 4-day work week gives an employee one extra day each week that he/ she can spend with the family, pursuing hobby, using for recreational purpose, leisure, personal work, etc. This results in a much better quality work-life balance which is hard to happen in case of a 5-dayor 6-day work week.

3. Better Employee Productivity: As a 4-day work week facilitates better work-life balance for the employees, it leads to better physical and mental health of the employees and results in less employee burnout. It enhances the concentration of the employees on the job and job satisfaction to a certain level as the employees are able to divide their time well between the professional and personal commitments. Employees working a four-day week are healthier, happier, and less time-pressured, according to a report in The Atlantic. These employees are found to be more focused and efficient. The feeling that the employer cares about them, give the employees a positive sense of wellbeing, research shows. The level of stress of these employees are found to be lower than the ones who work 5-day or 6-day a week. A study in New Zealand showed that the stress decreased by $7 \%$ among all employees involved and the overall work satisfaction increased by 5\%. (Ellis 2018)

4. Better Organizational Productivity: "It's not by running a sweatshop ... it's more about working smarter," Diamondback's CEO, Ben Eltz, told The Atlantic. A 4-day week facilitates the smart working as it is found to be related to more focussed work, lesser stress levels and enhanced professional commitment. In the UK alone, heavy workloads, as well as work-related stress and anxiety, are costing public services and companies millions each year, with one in four of all sick days being taken as a direct result of workload pressures. A 4-day work week is presumed to be lowering these negative impacts, thus increasing organizational productivity. "It is not just about how many hours you work, it's how productive and valuable they are and how you perceive this. The working day seems very long if it is wasteful and not enjoyable. Equally time 
flies when you are having fun. Ultimately the most important thing is that employees are happy in their jobs and being given the opportunity to work smartly." - Jos Creese, Digital Advisor. This in turn, improves the organizational productivity by not just working smarter, but also by working with more focus and dedication. It reduces the absenteeism of the employees due to ill health and is also related with better employee retention. All these factors lower the organizational costs while maintaining, if not always enhancing the organizational productivity.

5. Reduced Carbon Footprints globally: Research reveals that on an average an employee drives $17 \%$ lesser miles in the US on a weekend. This means that a four-day work week would reduce carbon emissions only in the U.S. by 45 million metric tons - more than the total emissions of U.S. states Oregon and Vermont combined. Having more quality time to be sent with the family would mean healthier and more sustainable choices. According to the World Economic Forum, "our current working time and lifestyle models are deeply intertwined with a fundamentally unsustainable economy, which demands us to endure long commutes due to overpriced housing and eat carbonintensive, frozen foods since we lack the time to prepare decent quality meals ourselves." (Citrix, The online cross-country survey 2019)

\section{Problems associated with 4-day Work Week:}

1. Need a Shift in Mind-set: The research suggests shows that most of us focus on objective and easily quantifiable performance metrics such as number of hours worked, rather than more qualitative metrics which would include overall organizational and/ or employee productivity and/ or well-being. If a 4-day work week has to be successful, then the organizations must shift their mind-sets to value actual productivity, not just hours worked. Organizations must make sure that employees need not worry about they being punished for prioritizing work-life balance, when their performance and overall productivity of the organization either remains unaffected and/ or is enhanced, despite working lesser number of days per week.

2. Widening Inequalities among Employees: A four-day work week may widen the existing inequalities between knowledge workers and manual workers. Whereas the knowledge workers generally get paid on a monthly basis, many of the manual workers are paid on an hourly basis which makes the time they spend at their workplace an absolute important criterion in deciding how much money they earn while working for a particular organization based on the time they spend working.

3. Increased Level of the Fatigue during the Work-week: If reduction in the days of a work-week leads to more number of hours to be spent by the employees on each working day, then it may result in a very high level of fatigue for the employees and actually adversely affect the employee productivity. (Martin 1974)

4. Marginal and/ or no Increase in the Job Satisfaction of the Employees in a long run: Though the 4-day work-week if found to enhance the job satisfaction among employees and is also found to be positively related to the employee morale, the research suggests that these are short-term phenomena. Once the employees get used to a 4-day work- 
week, its contribution towards job satisfaction and employee morale, starts diminishing. (Bird 2010)

5. Challenge for Managing Teams: Team management become growingly difficult in case of a 4-day work week, especially if the business is expected to operate 24/7. Team meetings whether physical or virtual become difficult when the days on which the team members work, get scattered. Managing the projects is difficult in such cases when all team members cannot be present for the most of the meetings and thus, are not on the same page always with respect to the ongoing work. It may also mean that the employees pressured to tune in on their days off, in order not to miss anything important.

6. Can't be applied to all kinds of Industries: Some industries operate on 24/7 basis. In case of such industries, 4-day work-week won' be a very practical approach to adopt. Especially the departments of the companies working for customer service, it is crucial to address customer issues during the weekdays and weekends, no matter which industry they are a part of.

\section{Conclusion:}

Though the concept of 4-day work week is again gaining a lot of attention after the COVID 19 pandemic and is considered to be one of the best options to be considered with respect to alternate working method to be implemented in the current COVID hit economy, its implementation is going to be a huge challenge for all those organizations that want to experiment with this work model. The organizations need to first and foremost change their attitude from "Slog Working" to "Smart Working. It would also need the employees to have a matured approach towards their work and have a focussed and committed mind-set towards their work. It is still too early to gauge, if a 4-day work week, can be future work week after the world has witnessed the COVID 19 pandemic and the unimaginable effects in has left for the entire world.

\section{References:}

- Bird, Robert C., "Four-Day Work Week: Old Lessons, New Questions Symposium: Redefining Work: Implications of the Four-Day Work Week - The Four-Day Work Week: Views from the Ground" (2010). Connecticut Law Review. 66. https://opencommons.uconn.edu/law_review/66

- Gannon M., Four Days, Forty Hours: A Case Study, CAL. MGMT. REV., Winter 1974

- Peeples L., Should Thursday Be the New Friday? The Environmental and Economic Pluses of the 4-Day Workweek, SCI. AM., July 24, 2009

- https://www.citrix.com > documents > analyst-report

- http://www.hse.gov.uk/statistics/causdis/stress.pdf

- https://www.adeccogroup.com/future-of-work/latest-insights/the-advantages-anddisadvantages-of-the-four-day-work-week/

- https://zapier.com/blog/four-day-work-week/

- https://www.weforum.org/agenda/2019/06/a-shorter-working-week-isnt-a-luxury-itsan-ecological-necessity/ 